\title{
EPIDEMIOLOGIA DA MÁ-OCLUSÃO NO BRASIL: REVISÃO DOS ASPECTOS ETIOLÓGICO E HISTÓRICO
}

\section{ARTIGO DE REVISÃo}

RODRIGUES, Thayza Cro Alfaro ${ }^{1}$

RODRIGUES, Thayza Cro Alfaro. Epidemiologia da má-oclusão no Brasil: revisão dos aspectos etiológico e histórico. Revista Científica Multidisciplinar Núcleo do Conhecimento. Ano 06, Ed. 06, Vol. 06, pp. 29-52. Junho de 2021. ISSN: 2448-0959, Link de acesso: https://www.nucleodoconhecimento.com.br/saude/etiologico-ehistorico, DOI: 10.32749/nucleodoconhecimento.com.br/saude/etiologico-e-historico

\section{RESUMO}

Os estudos epidemiológicos no Brasil, completos e de abrangência nacional, começaram a ser realizados somente no século 21. Até então, esparsos inquéritos eram vislumbrados com quase nula inferência nacional e não conseguiam refletir a realidade sobre as principais afecções na saúde oral da população brasileira. Somado a esse cenário, a maioria dos inquéritos, eram voltados, em sua maioria, para o monitoramento de cárie e doença periodontal. Ainda que representem as doenças mais prevalentes, não permitem as autoridades sanitárias enxergarem a gravidade de outros problemas bucais, dentre eles, a da má-oclusão dentária. Mesmo ocupando o terceiro lugar no ranking mundial dos principais problemas bucais, poucos são os levantamentos epidemiológicos nacionais voltados para investigação deste agravo. Portanto, o principal objetivo deste artigo, foi avaliar o real motivo pelo qual o Brasil encontra-se tão atrasado frente ao cuidado e prevenção da má oclusão no serviço público. Através de extensa revisão literária, foi organizado um panorama da evolução

\footnotetext{
${ }_{1}^{1}$ Pós-graduanda em Saúde Pública, pela Universidade Paulista. Graduação em Odontologia pela Universidade Santa Cecília.
}

$\mathrm{RC}: 88159$

Disponível em: https://www.nucleodoconhecimento.com.br/saude/etiologico-e-historico 
histórica dos levantamentos epidemiológicos brasileiros unido à análise dos principais fatores etiológicos que podem agravar a prevalência da má-oclusão. Infelizmente, concluiu-se que não há consenso na literatura quanto à veracidade dos dados obtidos através dos inquéritos oficiais, e tão pouco quanto aos fatores etiológicos, apesar de intrinsicamente correlacionados à saúde. Portanto, ainda há muito o que ser pesquisado para que a má oclusão seja foco de atenção nos programas brasileiros de saúde bucal.

Palavras-chave: Epidemiologia, má-oclusão, oclusopatia, prevenção, inquérito.

\section{INTRODUÇÃO}

A epidemiologia estuda o processo saúde-doença em coletividades humanas. Em geral, avalia-se a distribuição das doenças a partir dos fatores determinantes, danos instalados e eventos associados, propondo, de um lado, medidas específicas de prevenção, controle e erradicação de doenças e, de outro, coletando indicadores que sirvam de suporte ao planejamento, administração e avaliação das ações desenvolvidas em saúde (ROUQUAYROL, 1993; PEREIRA, 2003).

$\mathrm{Na}$ prática odontológica, seja em âmbito particular ou público, o estudo das populações atendidas rotineiramente exige dos profissionais conhecimento multidisciplinar em diversas áreas, dentre elas estatística, demografia, economia, sociologia e psicologia, no intuito de entender os determinantes e condicionantes das enfermidades bucais dentro de uma população alvo.

Historicamente, os inquéritos de saúde em escala surgiram, por sugestão da Organização Mundial de saúde (OMS), nos países desenvolvidos a partir de 1960, sendo tardiamente adotados pelos países subdesenvolvidos. Dada a precariedade dos sistemas de informação, os inquéritos eram a única fonte de informação de saúde confiável.

RC: 88159

Disponível em: https://www.nucleodoconhecimento.com.br/saude/etiologico-e-historico 
Os Estados Unidos realizavam seus primeiros levantamentos nacionais no fim da década de 50, por intermédio do National Center for Health Statistics (NCHS). Tais inquéritos foram os precursores dos atuais National Health and Nutritional Examination Surveys (NHANES), que também coletam dados em saúde bucal. Iniciativas do Canadá e de países da Europa, principalmente Reino Unido, apresentam bases de dados desde 1940. (RONCALLI, 2012; BARROS, 2008)

Em saúde bucal, a primeira obra a catalogar diversos estudos realizados desde a década de 30 nos Estados Unidos, demonstrando a distribuição das principais doenças bucais, foi "A epidemiologia da saúde bucal". Publicada em 1969, por Pelton, rompeu com o empirismo e favoreceu o desenvolvimento de diversos estudos epidemiológicos voltados à compreensão da etiologia da cárie e fluorose dentária, propiciando a criação do primeiro índice de avaliação: CPO. Dado o desenvolvimento histórico, os problemas mais estudados e tratados eram a cárie, fluorose e problemas periodontais.

A preocupação em se realizar levantamentos epidemiológicos voltados para a má oclusão em saúde pública ocorreu somente nos anos 70 devido, em parte, à redução dos problemas mais estudados nos países desenvolvidos, conforme citado há pouco. Passaram a existir diversos índices de avaliação das más-oclusões, desde a criação da Classificação de Angle em 1899, porém, na grande maioria, eram voltados para a propedêutica clínica, sendo difíceis de serem reproduzidos em larga escala graças aos vieses analíticos que compunham tais métricas.

Neste artigo, serão utilizadas as denominas oclusopatias e má-oclusões, ao invés de deformidades dento-faciais, conforme critério de avaliação preconizado pelo SB-2003. De acordo com Frazão (1998), a razão de não se utilizar de terminado termo, dá-se pelo significado muito abrangente e entidades que incluem, indo de fendas lábio palatinas às disfunções da articulação temporomandibulares.

Conceitualmente, a má-oclusão, na maior parte das vezes, não provém de um processo patológico específico. Trata-se de uma variação clínica significativa do RC: 88159

Disponível em: https://www.nucleodoconhecimento.com.br/saude/etiologico-e-historico 
crescimento normal, resultante da interação entre fatores ambientais e congênitos durante o desenvolvimento (BRASIL, 2008). Além da preocupação quanto ao correto desenvolvimento do sistema estomatognático, as questões estéticas também são importantes e devem ser levadas em conta, visto que interferem no bem-estar psicológico do indivíduo.

\begin{abstract}
A incidência de casos de má oclusão tem aumentado progressivamente, alcançando um número preocupante. Para que medidas de promoção da saúde e prevenção possam ser efetuadas, torna-se necessário o conhecimento da prevalência das más oclusões por meio de levantamentos epidemiológicos básicos, os quais oferecem uma base importante para se avaliar a situação atual e as futuras necessidades de cuidados de saúde bucal de uma população (CAMPOS, 2013).
\end{abstract}

Dada a importância dos estudos prevalência das más-oclusões, um resumo histórico será traçado para reflexões acerca do atraso de levantamentos epidemiológicos no Brasil. A seguir, serão apresentadas informações sobre os levantamentos epidemiológicos nacionais que puderam, de certa forma, refletir, em parte, a problemática existente. Além disso, será realizada uma breve abordagem à cerca dos fatores etiológicos que podem se comportar como fatores causais ou influentes da má-oclusão entre as crianças e adolescentes brasileiros.

\title{
2. REVISÃO BIBLIOGRÁFICA
}

\subsection{EPIDEMIOLOGIA DA MÁ OCLUSÃO: BREVE RESUMO HISTÓRICO}

\subsubsection{PAÍSES DESENVOLVIDOS}

A primeira publicação a classificar as oclusopatias, de forma clara e simples, foi a de Angle. Publicada em 1899, tornou-se o marco mais importante no desenvolvimento da ortodontia, entretanto apresentava limitações quanto a avaliação das más-oclusões nos sentidos vertical - transversal, além da falta de requisitos para ser considerado um instrumento epidemiológico. Ante sua fragilidade, vários autores propuseram RC: 88159

Disponível em: https://www.nucleodoconhecimento.com.br/saude/etiologico-e-historico 
outros sistemas para substituir o sistema; para isso, diversos testes e estudos comparativos foram realizados, mas nenhum foi largamente utilizado (PINTO, 2008).

$\mathrm{Na}$ tentativa de padronizar a categorização de doenças bucais para usos comparativos a nível internacional, a OMS, em 1961, publicou a Expert Committee on Dental Health. Nesta fase, a oclusão era classificada simplesmente em severa e não severa. A OMS, na sequência, publicou quatro edições de métodos básicos para avaliação de estudos epidemiológicos em saúde bucal que incluíam a análise da máoclusão de forma um pouco mais abrangente.

Em 1962, com o aumento gradativo da incidência das oclusopatias, a OMS passou a enfatizar a necessidade de análise epidemiológica de suas causas, através da aplicação de um índice simples, de fácil execução e reprodução, em que os dados obtidos pudessem ser comparados à nível mundial de forma que a origem dos problemas oclusais pudessem ser determinados.

Na primeira edição do Oral health surveys - basic methods, publicada em 1971, houve - acréscimo de dois novos critérios para avaliação da oclusopatia severa. Ainda neste período, a OMS reconheceu a falta de consenso entre os pesquisadores em relação a aceitação de um índice oclusal, sugerindo que de acordo com as características sanitárias, econômicas e políticas locais, os índices poderiam ser adaptados à realidade de cada região.

Em 1977, foi publicada a segunda edição do Oral health surveys: basic methods e uma classificação intermediária foi incluída: má-oclusão leve. Ato contínuo, na terceira edição publicada em 1987, foi apresentada uma nova metodologia para estudos populacionais, codificando e caracterizando as condições oclusais de crianças até 5 anos de acordo com método desenvolvido por Foster e Hamilton, em 1969, na Inglaterra.

Em 1991 foi publicada a edição em português da terceira edição do "Oral Health Surveys - basic methods", de 1987, um manual que objetiva fornecer instruções para a realização de levantamentos

RC: 88159

Disponível em: https://www.nucleodoconhecimento.com.br/saude/etiologico-e-historico 
epidemiológicos e tal publicação passou a servir de base a estudos realizados em diversos locais do Brasil (...) (OLIVEIRA, 1998).

A partir de 1997, com a publicação da quarta edição da Oral health surveys: basic methods, uma mudança acentuada é impressa às recomendações da OMS no que tange à mensuração de má-oclusão, e, se antes era preconizado um registro de natureza qualitativa, passou a ser recomendado o uso de um registro de natureza quantitativa (PINTO, 2008).

Com isso, a OMS passou a preconizar, pela primeira vez, o uso do Índice de Estética Dentária (DAI, Dental Aesthetic Index) para levantamentos epidemiológicos. Este índice foi criado, em 1986, na Universidade de Ohio, sob orientação do pesquisador Professor Natham C. Cons, sendo utilizado para avaliar a má-oclusão em idadesíndices de 12 e 15 anos.

Devido à preocupação histórica em prover inquéritos epidemiológicos voltados para saúde oral, países desenvolvidos como Inglaterra, Nova Zelândia, Suécia, Holanda e Finlândia passaram a oferecer, através dos sistemas públicos de saúde, tratamento ortodôntico para os casos mais graves ou deformantes justamente por compreenderem que práticas preventivas e interceptativas precoces reduzem, a longo prazo, o custo do tratamento.

Para triagem, o paciente é submetido a um índice classificatório, que determinará se há ou não necessidade de tratamento, e quando houver, será oferecido pelo Estado como benefício. O financiamento do tratamento ortodôntico, nestes países desenvolvidos, funciona de diversas formas, alguns adotam financiamento completo, outros concedem à iniciativa privada a prestação dos serviços. Algumas vezes, o custo do tratamento é repassado à família, gerando sistemas mistos de coparticipação que cobrem parcial ou totalmente os acometimentos mais complexos. (MACIEL, 2006).

RC: 88159

Disponível em: https://www.nucleodoconhecimento.com.br/saude/etiologico-e-historico 


\subsubsection{BRASIL}

A epidemiologia, no Brasil, utilizada para análise em saúde bucal, infelizmente é muito carente de informações. A produção de dados epidemiológicos obtidos por intermédio dos serviços de saúde (dados secundários) ou por levantamentos epidemiológicos (dados primários), pouco beneficiam os modelos assistenciais. O campo de trabalho nessa área é amplo e pouco atendido. A avaliação das más-oclusões não tem avançado em direção a uma perspectiva de saúde coletiva, predominando estudos com delimitações temáticas, morfológicas ou biomecânicas (RONCALLI, 2006; BITTENCOURT, 2016).

A necessidade em se produzir de uma base de dados nacional com dados epidemiológicos relevantes inicia-se muito tardiamente no Brasil, visto que boa parte dos países desenvolvidos apresenta séries históricas de monitoramento epidemiológico com início ainda no século 20. (RONCALLI, 2006)

Em termos de saúde bucal, os primeiros estudos epidemiológicos tiveram um início muito simplificado nos anos 50, através dos programas incrementais. Citados estudos possuíam abrangência restrita às áreas cobertas, comportando-se como iniciativas isoladas.

$\mathrm{Na}$ verdade, o Ministério da Saúde (MS) realizou seu primeiro levantamento epidemiológico em âmbito nacional somente em 1986, através da recém-criada Divisão Nacional de Saúde Bucal (DNSB), tendo seu relatório publicado somente em 1988. Foram pesquisados, então, dados relativos à cárie dentária, doença periodontal e acessos a serviços. Tratou-se de estudo de grande relevância por ser a primeira oportunidade em se obter dados de saúde bucal. Todavia, a pesquisa restringiu-se a 16 capitais, as quais representaram as 5 regiões naturais (Norte, Nordeste, Sudeste, Sul e Centro-oeste).

A Política de Saúde Bucal Nacional vinculada a este inquérito epidemiológico Programa de Prevenção da Cárie Dentária- restringiu-se a ações de baixa cobertura, RC: 88159

Disponível em: https://www.nucleodoconhecimento.com.br/saude/etiologico-e-historico 
que vislumbravam somente fluoretação das águas e aplicação tópica de flúor gel em escolares.

Importante destacar a situação histórico-política atravessada pelo país naquele momento. O Brasil acabara de sair de um período de ditadura militar, imposto desde 1964. Havia apenas dois anos que um presidente civil havia sido eleito por voto indireto (em 1984). No campo da saúde, a $8^{\circ}$ Conferência Nacional de Saúde consolidava o Movimento da Reforma Sanitária em 1986, e finalmente em 1988, ocorre a promulgação da Constituição Federal.

Em 1989, primeiro presidente por voto direto foi eleito iniciando uma nova fase da democracia brasileira. O processo de implantação do Sistema Único de Saúde (SUS), criado no ano anterior, era moroso e muitos quesitos que haviam sido garantidos pela Carta Magna deixaram de ser, de fato, implantados.

Na II Conferência Nacional de Saúde Bucal, realizada em 1993, definiu-se saúde bucal como parte integrante e geral da saúde do indivíduo, e, portanto, relacionada às condições de saneamento, alimentação, moradia, trabalho, educação, renda, transporte, lazer, serviços de saúde e informação. Para a OMS, os problemas de posicionamento dentário e mau relacionamento dos ossos maxilares, colocavam as más-oclusões dentárias como o terceiro problema odontológico de saúde pública, precedido apenas da cárie e problemas periodontais.

Após dez anos, em 1996, um segundo estudo nacional foi realizado graças à parceria entre o MS e o Conselho Federal de Odontologia. Nele apenas a cárie dentária foi pesquisada em grupo de idade-índice de 6-12 anos. A ideia principal era criar um escopo para que ações no Sistema Único de Saúde fossem desenvolvidas. No entanto, semelhante ao levantamento anterior, foi uma pesquisa fragmentada, e, infelizmente, o relatório final não chegou a ser publicado.

Em 2003, um projeto iniciado no final do segundo mandato de Fernando Henrique Cardoso e início do governo Lula, deu origem à primeira edição do Projeto SB-2000 -

RC: 88159

Disponível em: https://www.nucleodoconhecimento.com.br/saude/etiologico-e-historico 
Condições de Saúde Bucal da População Brasileira, posteriormente denominado SBBrasil 2003. Os critérios adotados, conforme orientação da 4a edição do Oral Health Surveys - basic methods, estão descritos no Manual do Examinador e no Manual do Anotador, produzidos pela equipe de coordenação do Projeto SB Brasil (BRASIL, 2004).

Trata-se do primeiro estudo epidemiológico mais completo e abrangente existente na área da saúde bucal do país. O Projeto SB-2000 surgiu para suprir a deficiências de estudos anteriores, compondo um diagnóstico consistente. Teoricamente, conseguiu se estabelecer um diagnóstico mais apurado da situação de saúde bucal levando em conta pontos nunca analisados, como as desigualdades regionais e o perfil de doenças inerentes à cada região.

Do ponto de vista metodológico, esse projeto avança ao propor um estudo que abrange um número considerável de municípios (250 ao todo, $50 \mathrm{em}$ cada região), superando a restrição dos estudos realizados somente em capitais, além de incluir a região rural. Pela primeira vez são incluídos, em um estudo nacional, municípios de pequeno porte. Outras inovações incluem a avaliação de praticamente todos os agravos mais importantes na área de saúde bucal (cárie dentária, doença periodontal, edentulismo, oclusopatias e fluorose) e uma composição de grupos etários que engloba todo o ciclo da vida. Além disso, foi incluída uma avaliação qualitativa, composta de três dimensões: condição socioeconômica, acesso a serviços de saúde e autopercepção de saúde bucal (RONCALLI, 2000).

Os dados coletados com o Projeto Saúde Bucal Brasil (SB-Brasil) forneceram importantes subsídios para a estruturação da Política Nacional de Saúde Bucal, conhecida como "Brasil Sorridente", promulgada em 2004. A política em questão nasceu num momento positivo, haja vista que fora incorporada ao Plano Nacional em Saúde, tornando-se prioridade no governo instalado. Com isso, financiamentos da área de saúde bucal foram ampliados, imprimindo ao "Brasil Sorridente" uma prática política consistente, algo até então inédito.

Comparado aos inquéritos anteriores, o SB Brasil 2003 incluiu ainda uma gama maior de dados relativos à situação socioeconômica, autoavaliação da saúde bucal e acesso aos serviços odontológicos (...) O planejamento deste inquérito considerou a seleção de uma

RC: 88159

Disponível em: https://www.nucleodoconhecimento.com.br/saude/etiologico-e-historico 
amostra probabilística por conglomerados, representativa de faixas etárias da população das cinco macrorregiões. O processo de amostragem, entretanto, não foi concluído. Faltou o cálculo dos pesos amostrais necessários para a produção de estimativas válidas para a população brasileira. Em 2004, houve a publicação dos seus principais resultados pelo Ministério da Saúde (...) diversos pesquisadores, que publicaram artigos científicos em revistas nacionais e internacionais sem perceberem que os resultados não eram inferências estatisticamente válidas para os grupos etários da população de pesquisa (brasileira ou por macrorregião) porque eram referidos e limitados ao grupo estudado (estatísticas da amostra) (QUEIROZ, 2009).

Em 2010, um novo levantamento epidemiológico Projeto SB-BRASIL foi realizado. Aperfeiçoamentos foram feitos, particularmente quanto à técnica de pesquisa em domicílios, tornando-se um processo histórico que se ampliou e se aprofundou a partir do Projeto SB Brasil 2003. Desta forma, consolidou-se como modelo metodológico e demarcou a atuação da vigilância em saúde através da Política Nacional de Saúde Bucal. (BRASIL, 2010)

Novos índices foram acrescentados, tal como a avaliação de traumatismo dentário, e outros modificados, por exemplo o CPI (Índice Periodontal Comunitário) e necessidade de prótese. Quanto ao plano amostral, as capitais foram consideradas como domínios do estudo, com maior racionalidade à pesquisa nos municípios do interior, compondo uma amostra de 30 municípios em cada região (totalizando 150), e o levantamento foi feito somente em domicílios da zona urbana (RONCALLI, 2012).

A OMS recomenda às autoridades sanitárias mundiais a realização de levantamentos epidemiológicos dos agravos em saúde bucal, numa periodicidade de cinco e dez anos, nas idades índice iniciais de 5, 12 e 15 anos, e sequencialmente, às faixas etárias de 35 - 44 e 65 - 74 anos. No ano de 2020, no Brasil, estava previsto novo levantamento epidemiológico em saúde bucal, no entanto, devido à pandemia provocada pela COVID-19, sua realização foi suspensa (FIGURA 1).

RC: 88159

Disponível em: https://www.nucleodoconhecimento.com.br/saude/etiologico-e-historico 
Figura 1 - Linha cronológica

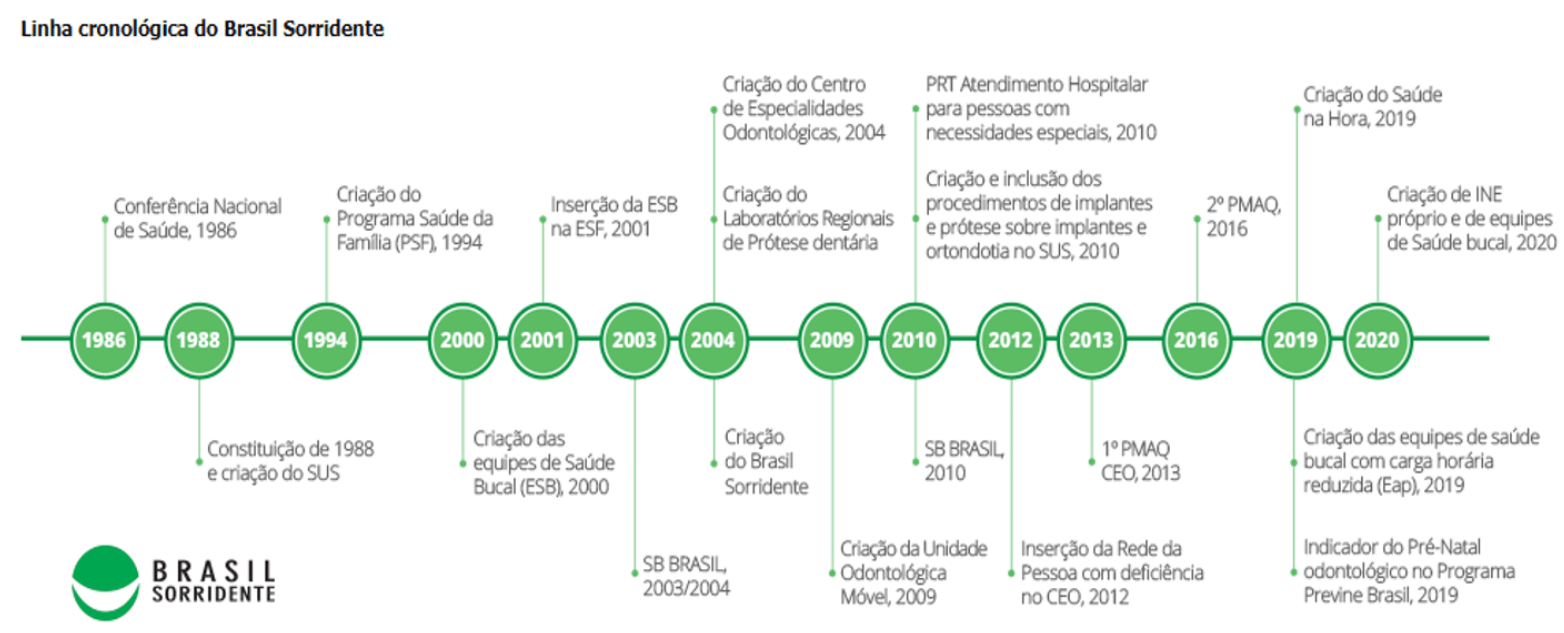

Fonte: Ministério da Saúde

\subsection{SB-BRASIL 2003 X SB-BRASIL 2010, O QUE MUDOU?}

\subsubsection{OCLUSOPATIAS ATÉ 5 ANOS}

Os problemas oclusais podem se desenvolver em idades precoces, sendo a autocorreção improvável. Portanto, a fase da dentição decídua é o período adequado para que medidas preventivas ou de tratamento sejam estabelecidos.

Foster e Hamilton estabeleceram critérios para uma classificação específica para os problemas oclusais na dentição decídua. Trata-se de um índice que considera algumas condições oclusais separadamente, sem atribuição de escores. São avaliados o espaçamento, apinhamento dentário, oclusão dos molares, relação de caninos, overjet, mordida cruzada anterior, overbite, mordida aberta anterior, mordida cruzada posterior (ANTUNES, 2013).

As oclusopatias mais frequentes são a sobressaliência, a sobremordida, a mordida aberta anterior e a mordida cruzada posterior, variando de acordo com a faixa etária estudada. $\mathrm{O}$ conhecimento da situação de saúde bucal e a prevalência das másoclusões de uma determinada região, por levantamentos epidemiológicos, possibilita o planejamento de medidas de prevenção,

$\mathrm{RC}: 88159$

Disponível em: https://www.nucleodoconhecimento.com.br/saude/etiologico-e-historico 
assim como de futuras necessidades de cuidados em saúde bucal (LEONCIO, 2015).

No SB-2003, 22,0\% da população de 5 anos de idade apresentava problemas oclusais considerados leves e 14,5\% apresentavam problemas moderados ou severos. Variações foram identificadas entre as regiões do país. O Centro-Oeste apresentava baixa prevalência de problemas oclusais leves, 19,7\%; por outro lado, considerando as oclusopatias moderadas ou graves, a região Sul apresenta a concentração mais alta, $19,4 \%$.

Segundo dados dos dois últimos inquéritos nacionais de saúde bucal da população brasileira a presença de algum problema oclusal nas crianças de 5 anos aumentou em $28,2 \%$ entre os dois levantamentos.(...) A prevalência da má oclusão entre os préescolares brasileiros, associada às macrorregiões brasileira e ao sexo dos pré-escolares, foi de 63,2\%, ou seja, esses indivíduos apresentaram pelos menos um dos problemas oclusais avaliados (chave de caninos, sobressaliência, sobremordida e/ou mordida cruzada anterior). Não tem sido bem esclarecido na literatura a caracterização do acometimento da má oclusão em crianças de 5 anos de idade considerando uma amostra representativa do Brasil, dificultando possíveis comparações (BAUMAN, 2018).

Dez anos depois, a prevalência de pelo menos um problema de má-oclusão, conforme requisitos do Índice de Foster e Hamilton, em crianças de cinco anos é de 66,7\%, segundo informações do SB Brasil-2010. Neste último levantamento epidemiológico, não houve divisão por critérios de agravamento quanto a oclusão, nos termos do SB2003 (normal, leve e moderada/severa). O Centro-Oeste, que apresentava um índice baixo de complicações dentárias, passou a apresentar 57\%, enquanto o Sul apresentou alta, ficando em primeiro lugar entre as regiões do país, com $71,6 \%$ das alterações oclusais.

\subsubsection{OCLUSOPATIAS EM IDADE ÍNDICE DE 12 ANOS}

A OMS define adolescência como a fase, dentro do ciclo de vida, que se inicia aos 10 anos de idade e termina aos 19 anos completos e divide-se em: pré-adolescência (10 aos 14 anos), adolescência (15 aos 19 anos completos) e juventude (15 - 24 anos).

RC: 88159

Disponível em: https://www.nucleodoconhecimento.com.br/saude/etiologico-e-historico 
Em 1997, a Organização adotou o Índice de Estética Dental - IED (Dental Aesthetic Index - DAI) como referência para a realização de levantamentos epidemiológicos de oclusopatias em adolescentes, sendo atribuído escores para problemas oclusais multiplicados por pesos distintos.

O índice individual é determinado pela somatória das multiplicações mais uma constante igual a 13, resultado que definirá a gravidade do problema estético dental. Este índice é recomendado para ser utilizado na dentição permanente completa o que, normalmente, ocorre a partir dos 12 anos de idade e vem substituindo o antigo índice para esta dentição (ANTUNES, 2013).

No Brasil, os últimos inquéritos epidemiológicos sobre os agravos bucais da população realizados nos anos de 2003 e 2010 mostraram uma redução de $19,3 \%$ na frequência de má oclusão, variando de $58,1 \%$ para $38,8 \%$ na idade de 12 anos. Em relação à severidade, em 2003 a condição severa foi de $15,7 \%$ e a muito severa de $20,7 \%$. Em 2010, para as mesmas condições, houve uma redução de 5,3\% e $13,6 \%$, respectivamente. Mesmo havendo uma queda da prevalência de má oclusão nas crianças com 12 anos de idade, esse acometimento ainda pode ser considerado um problema de saúde pública (BRIZON, 2013).

Em 2003, a prevalência de má-oclusão entre crianças de 12 anos na média nacional era de $58 \%$, sendo que $20 \%$ apresentavam condições muito severas. A região Sudeste foi a maior representante de casos com $24,79 \%$. Consoante o levantamento de 2010 , somente $7 \%$ das crianças avaliadas possuíam oclusopatias severas, e, novamente, a região Sudeste destacou-se com o maior percentual entre as regiões brasileiras, concentrando $9,1 \%$ dos casos. A região Sul, por sua vez, registrou o menor percentual, $5,3 \%$.

\subsubsection{OCLUSOPATIAS EM IDADE ÍNDICE DE 15-19 ANOS}

A adolescência é um período caracterizado por uma série de mudanças marcadas pela grande preocupação ligadas ao corpo, à imagem e à aparência. É nesse contexto que a saúde bucal ganha importância, por ser um componente do bem-estar e

RC: 88159

Disponível em: https://www.nucleodoconhecimento.com.br/saude/etiologico-e-historico 
felicidade individual. (ARAUJO, 2017). Para avaliação esta faixa etária também é utilizada o Índice DAI.

Segundo dados do SB-2003, 53,23\% dos adolescentes avaliados, em nível nacional, apresentavam má-oclusão. Destes, 18,75\% apresentavam condição severa ou incapacitante. O Nordeste, neste quesito, superou a média entre as regiões brasileiras, concentrando $19,91 \%$ dos casos severos de má-oclusão.

\begin{abstract}
O plano amostral do SBBrasil 2010 permitiu inferência tanto em nível nacional quanto no âmbito regional e municipal, nos domínios capital e interior. Do total de 4276 indivíduos estudados, a prevalência de adolescentes de 15-19 anos com má oclusão severa e muito severa foi de $17,5 \%$, o que representou uma redução de $15,3 \%$ na prevalência encontrada sete anos antes no SBBrasil 2003(...) A implantação da Política Nacional de Saúde Bucal, em 2004, o aumento das equipes de saúde bucal na Estratégia de Saúde da Família e a ampliação da população coberta por esses programas podem ter contribuído para reduzir o número de dentes perdidos por cárie em adolescentes e, consequentemente, para a redução da prevalência de má oclusão severa e muito severa verificada pelo SBBrasil2010 nesta faixa etária. (REBOUCAS, 2017)
\end{abstract}

No SB-2010, houve mudança no panorama nacional, e somente $9 \%$ dos adolescentes analisados apresentavam má-oclusão muito severa. O Nordeste passou a ocupar o quarto lugar em agravos oclusais muito severos, ao passo que as regiões Norte e Sudeste concentraram os primeiros lugares, $12,3 \%$ e 9,3\%, respectivamente

\title{
2.3 ETIOLOGIA DAS MÁS-OCLUSÕES: FATORES DETERMINANTES E CONDICIONANTES
}

A etiologia das más-oclusões é multifatorial, justamente por diversos fatores influenciarem o crescimento e o desenvolvimento dos maxilares. O conhecimento das possíveis causas da má-oclusão é de suma importância tanto para o ortodontista quanto para o sanitarista. A prevalência das más-oclusões vem aumentando, e, diante de diversos estudos, pesquisadores concluíram que um em cada quatro indivíduos possui má-oclusão (ALMEIDA, 2000).

RC: 88159

Disponível em: https://www.nucleodoconhecimento.com.br/saude/etiologico-e-historico 
Por serem inespecíficos, os fatores determinantes e condicionantes podem agir de modo isolado ou associado. Em primeiro lugar destaca-se a genética, seguida da hereditariedade, hábitos para-funcionais, tais como sucção digital ou de chupeta por mais de 18 meses, problemas otorrinolaringológicos que induzem à respiração bucal, entre eles desvios de septo, hipertrofia das adenoideana e postura incorreta da língua.

Além disso, merecem grande destaque traumas faciais e problemas odontológicos recorrentes, como a cárie e problemas periodontais. As cáries possuem influência direta sobre a dentição decídua, posto que grande parte das perdas precoces estão associadas a ela, sendo apontada, inclusive, como uma das principais causas da máoclusão na dentição permanente (BITTENCOURT, 2010).

A perda dentária, que já foi apontada como sendo o maior fator de risco para a má oclusão, é o componente de maior peso no cálculo do DAI, índice usado nos levantamentos de 2003 e de 2010. A perda precoce de dentes por cárie pode acarretar migrações dentárias que alteram as características oclusais dos indivíduos. Adolescentes com experiência de cárie avaliada pelo CPOD têm mais chances de apresentar alterações de linha média, mordida aberta e relação de molar de Classe II e III de Angle (REBOUCAS, 2017).

Teorias da evolução humana também são válidas e merecem destaque. Segundo a Teoria da Redução Terminal, a face humana passou por processo involutivo acompanhado do crescimento do crânio. Com a redução da face, e, consequentemente dos maxilares, o espaço para acomodar todos os dentes tornouse se limitado, inutilizando o último dente de cada série (terceiros molares, segundos pré-molares e incisivos laterais) que tendem a desaparecer (ALMEIDA, 2000).

Ainda nesse raciocínio, se a face involuiu, os hábitos alimentares também se modificaram. No passado, os alimentos eram mais duros e fibrosos exigindo um grande esforço muscular durante a mastigação; hoje, são pastosos, de fácil consumo, desestimulando o crescimento e desenvolvimento facial. Isso inclui a amamentação.

Atualmente, as mulheres, que predominam o mercado de trabalho, não dispõem de tempo para prover uma amamentação prolongada de seus bebês. Logo, todos os

RC: 88159

Disponível em: https://www.nucleodoconhecimento.com.br/saude/etiologico-e-historico 
fatores apresentados influenciam os padrões de desenvolvimento facial que alteram das mais diversas formas a oclusão.

\begin{abstract}
Parece evidente que o trabalho remunerado das mães as distância de seus filhos, que, de alguma maneira, buscam uma compensação emocional que se traduz na continuidade de hábitos bucais após a idade de três anos. A ocupação manual (da pessoa de maior renda no domicílio) predispôs à maior frequência de crianças com hábitos, o que indica que a falta de informações e baixo acesso a cuidados de saúde apresentados por este grupo podem repercutir negativamente no desenvolvimento infantil. Assim, determinantes socioeconômicos afirmam-se como variáveis causais em relação aos hábitos bucais. Estes afirmam-se como variáveis independentes ou causais em relação à má-oclusão, tanto em estudos epidemiológicos como nãoepidemiológicos (TOMITA, 2000).
\end{abstract}

Apesar da importância dos fatores clínicos, evolucionistas e hereditários, os determinantes sociais também são relevantes e tristemente negligenciados pela maioria dos profissionais em saúde que não compreendem a condição em que o indivíduo sobrevive. Associar pobreza a piores condições de saúde é ponto consolidado em pesquisas epidemiológicas, no entanto, o mecanismo pelo qual se desenvolvem, ainda é ponto obscuro na maioria dos estudos.

Em geral, pesquisas baseadas em grandes amostras tem precisão relativamente mais alta, podendo proteger o estudo de erro aleatório, embora o caráter transversal do delineamento não permita a inferência de causalidade às associações encontradas (REBOUÇAS, 2017).

As diferenças no estado de saúde de determinados grupos são definidas por disparidades em características como riqueza, educação, ocupação, etnia, gênero e condições do local de moradia ou trabalho. Portanto, a organização social determina desigualdades na saúde (BARATA, 2009).

O princípio da equidade, norteador do Sistema Único de Saúde, apesar de dar direito de acesso à saúde considerando as particularidades de cada indivíduo, coloca à prova a ideia de justiça social, vez que o trato das pessoas em risco social ainda é muito limitado.

RC: 88159

Disponível em: https://www.nucleodoconhecimento.com.br/saude/etiologico-e-historico 
Fatores de risco e de proteção podem incidir de modo desigual sobre os estratos sociais, com efeitos deletérios ou salutares que atingem a população de modo heterogêneo e aumentam as desigualdades em saúde. A redução da pobreza de um país traz melhorias para as condições de vida das pessoas, o que reflete positivamente na saúde da população (ANTUNES, 2013).

Como não poderia ser diferente, a má-oclusão possui maior prevalência entre indivíduos não brancos com menor renda familiar. A vulnerabilidade inerente à população parda/negra aliada a fatores sociais (baixo índice de desenvolvimento humano, distribuição de renda desigual e dificuldade de acesso a políticas de cuidado em saúde), podem auxiliar no entendimento lógico dos agravos em saúde bucal.

Apesar de haver evidências de que a má oclusão se associa com a pior condição socioeconômica com a presença de problemas dentários como a cárie, com a perda dentária e com a doença periodontal, os resultados têm sido diversos e a presença de associação entre estes aspectos e a má oclusão não está clara. Parte desta divergência pode estar relacionada ao uso de diferentes índices de avaliação da má oclusão (REBOUCAS, 2017).

Entre os levantamentos epidemiológicos nacionais em saúde bucal, o Brasil passou por um período de crescimento econômico, que foi o principal responsável pela redução da pobreza extrema. Nesse contexto, foi criado o Programa Bolsa Família em 2004 pelo governo federal. Este programa social, ainda vigente, prevê a transferência renda às famílias em situação de pobreza e de extrema pobreza.

Com isso, o Brasil reduziu a extrema pobreza a menos de um sétimo do nível de 1990, de $25,5 \%$ para $3,5 \%$ em 2012, ultrapassando a meta global dos Objetivos de Desenvolvimento do Milênio estabelecido pela Organização das Nações Unidas de reduzir a pobreza extrema à metade do nível de 1990 até 2015.

A ideia principal era que a redução da pobreza de um país trouxesse melhorias para as condições de vida com reflexos positivos na saúde. Porém, se critérios educacionais e abordagens de controle e rastreamento não forem adotados, o simples

RC: 88159

Disponível em: https://www.nucleodoconhecimento.com.br/saude/etiologico-e-historico 
fato de ocorrerem melhoras quanto à distribuição de renda não garantirá a melhora dos agravos de acometimento oral.

Em geral, populações de baixa renda gastam grande parcela de sua renda em alimentos não saudáveis, com alta concentração de açúcares e gorduras, e mesmo que os ganhos fossem realocados para aquisição de frutas, hortaliças, leite e derivados não seria possível alimentar uma família inteira, pois a renda seria insuficiente para suprimir os gastos com alimentação (BORGES, 2015).

Logo, o problema torna-se cíclico: má alimentação, consumo de alimentos cardiogênicos, falta de programas preventivos de educação em saúde oral, aumento de cáries, aumento do índice CPOD, e, por fim, aumento das más-oclusões. Programas e iniciativas em saúde, introduzidos sem a necessária atenção para o problema da desigualdade social, muitas vezes pioram a posição relativa dos grupos de população mais submetidos à privação, no que diz respeito à prevalência de doenças e ao risco de mortalidade (ANTUNES, 2013).

O relatório do SB Brasil 2010 mostrou que $54,3 \%$ das crianças de até 5 anos de idade apresentaram, em média, 2,43 dentes com cárie, com predomínio do componente cariado, que é responsável por mais de $80 \%$ do índice. No entanto, para o Nordeste, o ceo-d médio atingiu o valor de 2,89, e o componente cariado correspondeu a $88,2 \%$. Em contrapartida, as crianças examinadas beneficiadas pelo Programa Bolsa Família desde o seu nascimento, apresentaram um ceo-d médio de 4,77 e o componente cariado correspondeu a $81,8 \%$ dessa média, de forma que a comparação desses dados epidemiológicos apontara para a permanência de fortes iniquidades em saúde, uma vez que os resultados foram quase duas vezes $(1,95)$ superior ao resultado regional (JUNIOR, 2013).

Nada obstante o acesso aos serviços odontológicos ser de suma importância, as diferenças de necessidades nunca serão totalmente eliminadas, porém é inegável que acesso a serviços de qualidade pode amenizar condições desfavoráveis (GIBILINI, 2010).

RC: 88159

Disponível em: https://www.nucleodoconhecimento.com.br/saude/etiologico-e-historico 
Em 2003, 14\% dos adolescentes brasileiros nunca haviam ido ao dentista. As desigualdades regionais eram marcantes: $22 \%$ dos jovens nordestinos nunca haviam consultado um dentista contra apenas $6 \%$ da Região Sul.

Os que compareciam aos serviços de atendimento odontológico para consultas de rotina perfaziam um total de 34\%, com concentração em nas regiões Sul, $47,40 \%$, e Centro-Oeste $36,96 \%$, com grande concentração nos serviços públicos, por ouro lado, $30 \%$ dos adolescentes referiram que o principal motivo era a dor, representados em maior proporção pela região Norte e Nordeste com 40,16\% e 32,19\%, respectivamente (BRASIL, 2003).

Em 2010, houve alguma melhora no atendimento. A Região Sul destacou-se com a menor prevalência de adolescentes que nunca se consultaram com o dentista no País (5,0\%), contra 13,6\% no Brasil. Em todas as regiões, a utilização do serviço público novamente foi a mais utilizada, principalmente pela Região Norte $(65,4 \%)$, seguida da Região Sudeste (43,2\%), da Região Sul (41,3\%) (BRASIL, 2010).

Historicamente, a prestação dos serviços odontológicos em saúde pública no Brasil era de baixa complexidade, curativo e de acesso restrito. Diante de tantos tratamentos mutiladores, além do edentulismo, o elevado índice de insatisfação com saúde oral reflete a falta de importância com que era tratada.

A autopercepção da saúde baseia-se em critérios subjetivos e objetivos, sendo um bom preditor de mortalidade e refletindo uma percepção individual, que inclui aspectos biológicos, psicológicos e sociais. (AGOSTINHO, 2010).

Segundo a OMS, qualidade de vida é a percepção do indivíduo de sua posição na vida, no contexto da cultura e sistema de valores nos quais ele vive e em relação aos seus objetivos, expectativas, padrões e preocupações.

Logo, a mensuração em autopercepção e qualidade de vida podem ser parâmetros de avaliação quanto às políticas públicas implantadas, já que evidências científicas

RC: 88159

Disponível em: https://www.nucleodoconhecimento.com.br/saude/etiologico-e-historico 
vinculam a autopercepção negativa da saúde aos indicadores de iniquidades sociais (GABARDO, 2013).

Nos inquéritos nacionais foi incluído o índice de autopercepção da saúde bucal. Neles, crianças até 5 anos não foram avaliadas, somente adolescentes. No SB-2003, adolescentes de 15 a 19 anos foram entrevistados, relataram uma situação de saúde bucal péssima em 44\%, ruim ou regular em 44,7\% e finalmente, $22,8 \%$ declararam possuir alguma dificuldade mastigatória.

Já no SB-2010, jovens de 12 anos também foram entrevistados e 47\% estavam satisfeitos com seus dentes e suas bocas, não havendo variação significativa entre as regiões. Por outro lado, verificou-se que a prevalência de insatisfação, entre jovens entre os 15 e os 19 anos, foi menor, representado $20 \%$ dos avaliados.

Nas regiões Sudeste (18,0\%), Sul (16,0\%) e Centro-Oeste (19,5\%), a prevalência de insatisfação com seus dentes e suas bocas foi significativamente menor do que a constatada nos jovens da mesma faixa etária da Região Norte (36,2\%). Para os adolescentes, em ambas as faixas etárias, as condições orais que mais afetam a vida diária são comer, escovar os dentes, estado emocional e sorrir. Compreender a prevalência da má-oclusão entre os adolescentes que vivem em condições de maior vulnerabilidade pode apontar um outro indicador: a exclusão social.

Conforme estudos em psicossociologia, a atratividade facial é fator importante na interação social. As pessoas com aparência facial satisfatória são consideradas ativas, amistosas e possuem mais facilidade em iniciar um relacionamento afetivo, e, assim, a condição oral ajuda a compor todo o conjunto estético da face.

A autopercepção em adolescentes deve ser vista como de fundamental importância na compreensão do impacto da má-oclusão em sua vida diária, especialmente em relação às limitações funcionais e ao bem-estar psicossocial.

RC: 88159

Disponível em: https://www.nucleodoconhecimento.com.br/saude/etiologico-e-historico 
estabilidade psicológica da criança, pois pode impor a ela situações que a marcarão (MACIEL, 2006).

Agressões psicológicas podem causar desordens no comportamento e desajustes na personalidade. Pessoas agredidas passam a ser mais resignadas e estoicas, comportando-se passivamente diante das situações desfavoráveis. Dessa forma, a má-oclusão também interfere na saúde mental, de forma indireta.

\section{DISCUSSÃO}

Os levantamentos SB-Brasil 2003 e SB-BRASIL 2010 foram pioneiros em mensurar, a nível nacional, a realidade da condição oral brasileira. Apesar de considerados marcos históricos dos estudos epidemiológicos em saúde bucal no Brasil, diversas críticas Ihes são direcionadas.

Para muitos estudiosos, a forma e distribuição com que os resultados foram obtidos, apresentam dados equivocados que não servem como fonte fidedigna, sendo, inclusive, sua utilização para comparações em ações futuras questionadas.

Infelizmente, os problemas da amostra do SB Brasil 2003 não se limitam à ausência dos pesos amostrais. Para estimar variâncias e demais estatísticas dela dependentes (erros padrão, intervalos de confiança, significância de parâmetros de modelos estatísticos, dentre outras) é necessário, também, conhecer as outras informações estruturais do desenho da amostra: o estrato de seleção e a unidade primária de amostragem. Isto deriva do fato de o plano de amostragem do SB Brasil 2003 ser complexo, combinando estratificação, conglomeração e seleção com probabilidades desiguais. Ou seja, um plano amostral que não permite estimação baseada na inferência estatística clássica, visto não ser aplicável um de seus pressupostos básicos: o de que todas as unidades da amostra derivam de observações independentes e igualmente distribuídas (QUEIROZ, 2009).

Em ambos os levantamentos epidemiológicos nacionais para análise das oclusopatias foram utilizadas a idade índice de 5 anos para pré-escolares, avaliada pelo Índice de Foster e Hamilton, seguida pelas idades índices de 12 e intervalo de 15-19 anos, avaliados pelo Índice DAI.

RC: 88159

Disponível em: https://www.nucleodoconhecimento.com.br/saude/etiologico-e-historico 
Estas idades índices foram preconizadas pela OMS em sua $4^{\circ}$ edição da Health Oral. Todavia, também existem críticas direcionadas ao índice DAI aplicado para análise das condições bucais dentro das faixas de idades-índices propostas pela OMS.

\begin{abstract}
Apesar de o DAI ser recomendado pela OMS e ter sido mundialmente usado em estudos sobre a necessidade de tratamento ortodôntico este índice pode subestimar a ocorrência de oclusopatias por não incluir condições como mordida cruzada posterior, mordida profunda, ou alterações de linha média, o que pode trazer limitações para este estudo. Além disso, fatores frequentemente relacionados à má oclusão como retenção prolongada de dentes decíduos, traumatismo em região de face, padrão respiratório buco nasal, hábitos de sucção, interposição lingual e deglutição atípica não foram avaliados no SBBrasil e não foi possível avaliar a associação destes agravos com a má oclusão (REBOUÇAS, 2017).
\end{abstract}

Apesar de não ser muito discutida entre os artigos científicos, as particularidades raciais existentes entre as regiões do país impedem a verificação dos reais motivos que originam as más-oclusões.

O fato do Brasil ser um país de dimensões continentais somada à intensa miscigenação racial, torna quase que impossível a tarefa de descrever através de índice proveniente de um país europeu ou americano, um roteiro de características oclusais anômalas, na medida em que são desconsideradas as particularidades raciais inerentes à cada região.

\begin{abstract}
A hereditariedade constitui um dos principais fatores etiológicos prénatais das más oclusões. O padrão de crescimento e desenvolvimento sofre forte influência dos fatores hereditários. Existem certas características raciais e familiares que podem comprometer a morfologia dentofacial de um indivíduo. Por exemplo, um jovem pode herdar o tamanho e a forma dos dentes do pai e o tamanho e a forma dos maxilares da mãe, resultando em uma combinação harmoniosa ou não entre os ossos e os dentes. Entretanto, não é possível prevenir tal combinação indesejada. (...) Nas populações raciais homogêneas (grupos geneticamente puros) quase não se observa má oclusão, enquanto nos grupos que apresentam grande miscigenação racial a prevalência de más oclusões aumenta substancialmente(...)atualmente, observa-se um intenso cruzamento entre as raças branca, negra e amarela contribuindo sobremaneira para o aumento das más oclusões (ALMEIDA, 2006).
\end{abstract}

$\mathrm{RC}: 88159$

Disponível em: https://www.nucleodoconhecimento.com.br/saude/etiologico-e-historico 
O Brasil é um país constituído, basicamente, por quatro etnias: o branco europeu, o negro africano, indígena e os orientais distribuídos desigualmente pelo espaço territorial brasileiro. Com a miscigenação de raças no passar dos anos ocorreu uma mistura de vários padrões faciais e oclusais, ocasionando diferentes más oclusões, dificultando o diagnóstico, diferente de outras partes do mundo (CAVASSOLA, 2014).

Além disso, durante levantamento bibliográfico para este artigo, foi possível observar entre os diversos levantamentos epidemiológicos realizados em diferentes regiões do país, que os índices utilizados eram heterogêneos entre si, sendo o IONT (Index of Orthodontic Treatment Need) o mais utilizado.

Conquanto recomendados pelos países desenvolvidos, não foram utilizados nos levantamentos epidemiológicos oficiais a nível nacional, dificultando qualquer comparação formal entre os índices obtidos e os provenientes das análises segmentadas.

O OITN foi proposto, em 1989, por Shaw e Brook. Modificado por Richmond, em 1990, ganhou reconhecimento internacional como o método mais objetivo para a classificar as más-oclusões de acordo com sua gravidade. O OITN é composto em duas partes: um Índice Estético, Aestethic Index (AI) e o Índice de Saúde Dental, Dental Health Component (DHC), que podem ser aplicados de maneira independente (MACIEL, 2006).

Fato de ser um dado ainda irrelevante, por um lado em virtude da inexistência de políticas claras de intervenção neste tipo de doença e, por outro, pela constatação de que o maior problema ainda é a cárie dentária, de modo que eventuais problemas de má-oclusão percebidos em levantamentos nada mais são que sequelas de perdas dentárias pela cárie (ALMEIDA, 1998).

Malgrado as recomendações da OMS, em sua base de dados voltadas para saúde bucal há pouquíssimas informações sobre o perfil de má-oclusão dos países que utilizaram sua metodologia. A análise de má-oclusão, apesar do aumento de prevalência, permanece em segundo plano. $O$ que se entende é que ações

RC: 88159

Disponível em: https://www.nucleodoconhecimento.com.br/saude/etiologico-e-historico 
preventivas contra a cárie dentária ainda são prioridade em saúde pública na maior parte dos países, e, que de certa forma, também ajudariam a prevenir os problemas de oclusão.

\section{CONCLUSÃO}

Unido ao atraso histórico de levantamentos epidemiológicos e pequeno avanço sobre a importância da saúde bucal brasileira está a falta consenso sobre a forma de mensuração da má-oclusão no Brasil. Diversos estudos são publicados anualmente, porém sem considerar um padrão ou índice que facilite a comparação histórica dos dados obtidos. De forma muito grosseira, baseado em índices oficiais obtidos através dos levantamentos epidemiológicos SB 2003 e SB 2010, é possível concluir que a incidência da má-oclusão entre crianças cresceu e em adolescentes involuiu. Entretanto, há se de ter em mente que esses índices comparam dados mensurados de modo diferente e em situações socioeconômicas distintas.

Como já dito anteriormente, a condição de saúde de uma população caminha paramente com sua condição socioeconômica. O fato é, que, infelizmente, no Brasil não há grande investimento por parte dos governantes na área. Educar em saúde uma população depende do acesso a serviços que quase sempre estão disponíveis à pequena parcela da população, e, entre eles, está o tratamento ortodôntico, que muitas vezes é tido como puramente estético.

Não suficiente, devido à pandemia, o Brasil está entre os países com maior desigualdade em distribuição de renda, de acordo com o relatório do Programa das Nações Unidas para o Desenvolvimento (PNUD). O PNUD avalia a discrepância dos diferentes segmentos da população de 0 a 100 zero em escala mundial, e o Brasil apresenta coeficiente 56,3. Porém, não se deve esquecer que dessa população total, pretos e pardos representam $70 \%$ das pessoas abaixo da linha de pobreza, segundo os parâmetros do Banco Mundial.

RC: 88159

Disponível em: https://www.nucleodoconhecimento.com.br/saude/etiologico-e-historico 
Apesar da importância prestada à ortodontia interceptativa, principalmente nos países desenvolvidos, no Brasil, sua implantação no âmbito do SUS ainda é um sonho muito distante. Ainda que mais tangível, de fácil aplicabilidade e baixo custo operacional, a ortodontia preventiva, que nem sempre requer a utilização de aparelho ortodôntico propriamente dito, não dispõe de nenhum protocolo dentro dos serviços públicos que possibilite, de fato, que as más-oclusões dentárias sejam evitadas.

Quando executada de forma correta e no devido tempo, a ortodontia preventiva é capaz de prevenir diversos tratamentos de longo prazo onerosos, dentre os quais a extração de dentes permanentes e cirurgias ortognáticas.

De certo, sabemos que ações preventivas de outros males ajudam a diminuir a prevalência das oclusopatias, tais como a prevenção e tratamento de cáries e problemas periodontias. Ocorre que isso não é suficiente em meio a tantos problemas sociais que o país enfrenta. Ainda dependemos de um processo evolutivo das questões humanitárias, para quem sabe, um dia, a saúde bucal seja realmente levada a sério, principalmente no que concerne à má-oclusão, que tanto afeta a vida de milhares de crianças e adolescentes brasileiros.

\section{REFERÊNCIA}

AGOSTINHO, Milena Rodrigues et al. Autopercepção da saúde entre usuários da Atenção Primária em Porto Alegre, RS. R. bras. Med. Fam. e Comun., Florianópolis, v. 5 , n. 17 , p. $9-15$, jan./dez. 2010

ALMEIDA et al . Etiologia das Más Oclusões - Causas Hereditárias e Congênitas, Adquiridas Gerais, Locais e Proximais (Hábitos Bucais) R Dental Press Ortodon Ortop Facial, Maringá, v. 5, n. 6, p. 107-129, nov./dez. $2000-2000$

ANTUNES, José Leopoldo Ferreira; PERES, Marco Aurélio; JUNIOR, Oswaldo Crivello. Epidemiologia da saúde- 2. ed. - São Paulo : Santos, 2013.

RC: 88159

Disponível em: https://www.nucleodoconhecimento.com.br/saude/etiologico-e-historico 
ARAÚJO, Marizeli Viana de Aragão et al. Prevalência de cárie dentária, autopercepção e impactos em saúde bucal em adolescentes na ilha do Marajó - Pará. RDAPO: Revista Digital da Academia Paraense de Odontologia. Belém-PA, v.1, n.1, p: 11-17, mai. 2017

Barata, Rita Barradas. Como e Por Que as Desigualdades Sociais Fazem Mal à Saúde. / Rita Barradas Barata. Rio de Janeiro: Editora Fiocruz, 2009. Disponível em:<https://static.scielo.org/scielobooks/48z26/pdf/barata-9788575413913.pdf>. Acesso em 10/05/2021.

BARROS, Marilisa Berti de Azevedo. Inquéritos domiciliares de saúde: potencialidades e desafios. Rev Bras Epidemiol; São Paulo, v.11, n.1, p: 6-19, mai.2008

BAUMAN, José Mansano et al. Padrão epidemiológico da má oclusão em préescolares brasileiros. Ciência \& Saúde Coletiva, São Paulo, v.23, n.11, p: 3861-3868, nov.2018.

BITTERCOURT, Marcos Alan Vieira; MACHADO, André Wilson. Prevalência de má oclusão em crianças entre 6 e 10 anos - um panorama brasileiro. Dental Press J. Orthod. Maringá, v.15, n.6, p. 113-122, dez./2010

BORGES, Camila Aparecida et al. Quanto custa para as famílias de baixa renda obterem uma dieta saudável no Brasil? Cad. Saúde Pública, Rio de Janeiro, v.31, n.1, p:137-148, jan.2015

BRASIL. Ministério da Saúde. Secretaria de Atenção à Saúde. Departamento de Atenção Básica. Saúde Bucal / Ministério da Saúde, Secretaria de Atenção à Saúde, Departamento de Atenção Básica. - Brasília : Ministério da Saúde, 2008. 92 p. - (Série A. Normas e Manuais Técnicos) (Cadernos de Atenção Básica; 17)

BRASIL. Ministério da Saúde. Projeto SB Brasil 2003. Condições de saúde bucal da população brasileira 2002-2003. Resultados principais. Brasília, 2004.

RC: 88159

Disponível em: https://www.nucleodoconhecimento.com.br/saude/etiologico-e-historico 
BRASIL. Ministério da Saúde. Projeto SB Brasil 2010. Pesquisa Nacional de Saúde Bucal. Resultados Principais. Brasília, 2012

BRIZON, Valéria Silva Cândido et al. Fatores individuais e contextuais associados à má oclusão em crianças brasileiras. Rev Saúde Pública, São Paulo, v.47, n.3, p:11828, mar.2013

CAMPOS et al. A má oclusão e sua associação com variáveis socioeconômicas, hábitos e cuidados em crianças de cinco anos de idade. Rev Odontol UNESP,São Paulo, v.42, n.3, p: 160-166, mar.2013

CAVASSOLA, Wállace. Prevalência de maloclusão em escolares de 7 a 8 anos. Monografia( Especialização em Ortodontia) - FUNORTE/SOEBRAS, Instituto de Ciências Da Saúde, Caxias do Sul, 2014.

FRAZÃO, Paulo. Epidemiologia da oclusão dentária na infância e os sistemas de saúde. Monografia (Tese de Doutorado). Faculdade de Saúde Pública da Universidade de São Paulo. São Paulo, 1999.

GIBILINI, Cristina et al. Acesso a serviços odontológicos e autopercepção da saúde bucal em adolescentes, adultos e idosos. Arquivos em odontologia Belo Horizonte, v 46, n 4. p: 213-223, out/dez 2010

GABARDO, Marilisa Carneiro Leão; MOYSÉS, Simone Tetu ; MOYSÉS, Samuel Jorge. Autopercepção de saúde bucal conforme o Perfil de Impacto da Saúde Bucal (OHIP) e fatores associados: revisão sistemática. Rev Panam Salud Publica Washington - United States.v. 33, n. 6, p:439-45, jan.2013

JUNIOR, Valdeci Elias dos Santos Junior et al. O impacto de um programa social brasileiro sobre a saúde bucal de crianças. RFO, Passo Fundo, v. 18, n. 1, p:61-66, jan./abr. 2013

RC: 88159

Disponível em: https://www.nucleodoconhecimento.com.br/saude/etiologico-e-historico 
LEONCIO et al. Prevalência de má-oclusão em crianças de cinco anos de idade do município de Patos, PB - Arq Odontol, Belo Horizonte, v.51, n.1, p: 25-31, jan./mar 2015

MACIEL, Sérgio Murta ; KORNIS, George Edward Machado . A ortodontia nas políticas públicas de saúde bucal: um exemplo de eqüidade na Universidade Federal de Juiz de Fora. Physis. Rio de Janeiro, v.16, n.1, p.59-81, jan./jul 2006

MINISTERIO DA SAÚDE - PORTAL DA SECRETARIA E ATENÇÃO PRIMÁRIA EM SAÚDE. Disponível em: < https://aps.saude.gov.br/ape/brasilsorridente/sbbrasil2020 $>$. Acessado em 28/04/2021.

MOREIRA, Andressa Ferreira et al. Impacto da má oclusão na dentição decídua e permanente na qualidade de vida de crianças e adolescentes: revisão de literatura. Rev. Bras. Odontol. Rio de Janeiro, v.72 n.1-2, jan./jun. 2015

OLIVEIRA, Angelo Giuseppe Roncalli da Costa et al. Levantamentos epidemiológicos em saúde bucal: análise da metodologia proposta pela Organização Mundial da Saúde. Rev. bras. epidemiol., São Paulo, v. 1, n. 2, p. 177-189, ago. 1998

PEREIRA, A.C. $P$ et al. Odontologia em saúde coletiva: Planejando ações e promovendo saúde. Porto Alegre: Artmed, 2003.

PINTO, Edvaldo de Melo; GONDIM, Pedro Paulo da Costa; LIMA, Neide Siqueira de. Análise crítica dos diversos métodos de avaliação e registro das más oclusões. Rev. Dent. Press Ortodon. Ortop. Facial, Maringá , v. 13, n. 1, p. 82-91, feb. 2008.

QUEIROZ, Rejane Christine de Sousa; PORTELA, Margareth Crisóstomo; VASCONCELLOS, Mauricio Teixeira Leite. Pesquisa sobre as Condições de Saúde Bucal da População Brasileira (SB Brasil 2003): seus dados não produzem estimativas populacionais, mas há possibilidade de correção. Cad. Saúde Pública, Rio de Janeiro, v.25, n.1, p:47-58, jan. 2009

$\mathrm{RC}: 88159$

Disponível em: https://www.nucleodoconhecimento.com.br/saude/etiologico-e-historico 
REBOUÇAS, Adriana Gama et al. Fatores individuais associados à má oclusão em adolescentes Ciência \& Saúde Coletiva, Rio de Janeiro, v.22, n.11, p:3723-3732, nov. 2017

RONCALLI, Angelo Giuseppe Roncalli. Epidemiologia e saúde bucal coletiva: um caminhar compartilhado. Ciência e Saúde Coletiva Rio de Janeiro, v.11, n.1, p: 105114, mar. 2006

RONCALLI, Angelo Giuseppe Roncalli; CÔRTES, Maria Ilma de Souza; PERES, Karen Glaze. Perfis epidemiológicos de saúde bucal no Brasil e os modelos de vigilância. Cad. Saúde Pública, Rio de Janeiro, 28 Sup:S58-S68, 2012

ROUQUAYROL, Maria Zélia, 1993. Epidemiologia e Saúde. 4ª ed., Rio de Janeiro: MEDSI.

SANTOS, Letícia Mendes et al. Autopercepção sobre saúde bucal e sua relação com utilização de serviços e prevalência de dor de dente. Revista Ciência Plural. Natal/RN. v 2, n. 2, p: 14-27, dez. 2016

TOMITA, Nilce Emy; SHEIHAM, Aubrey; BIJELLA, Vitoriano Truvijo; FRANCO, Laércio Joel. The relationship between socioeconomic determinants and oral habits as risk factors for malocclusion in preschool children. Pesq Odont Bras, São Paulo. v. 14, n. 2, p. 169-175, abr./jun. 2000

Enviado: Maio, 2021.

Aprovado: Junho, 2021.

RC: 88159

Disponível em: https://www.nucleodoconhecimento.com.br/saude/etiologico-e-historico 